\title{
Detection and Analysis of the Main Routes of Voluntary Observing Ships in the North Atlantic
}

\author{
Roberto Vettor and C. Guedes Soares \\ (Centre for Marine Technology and Engineering (CENTEC) Instituto Superior \\ Técnico, Universidade de Lisboa, Portugal) \\ (E-mail: c.guedes.soares@centec.tecnico.ulisboa.pt)
}

The main routes of ships voluntarily completing meteorological observations across the North Atlantic are detected by the intensity of the geographical distribution of the voluntary ship observations. The routes are then analysed in order to assess the relative intensity of traffic, the seasonal changes and the trend over the years. This paper will provide a better understanding of the North Atlantic trades and the relationship among the different routes, allowing the identification of the busiest areas. A discussion over the impact of routing on the weather that a transoceanic ship can experience during its life is also provided.

\section{KEY WORDS}

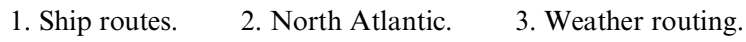

Submitted: 20 November 2013. Accepted: 8 October 2014. First published online: 5 November 2014.

1. INTRODUCTION. $90 \%$ of international trade travels by sea. Although the global economy is undergoing many changes (Rodrigue et al., 2006; UNCTAD, 2007) the North Atlantic continues to have an important role in the marine transportation system. Knowing the main sea routes between Europe and North America, together with their continuous evolution during the years and the seasons, is fundamental to ensure maritime safety and to survey the oceanic traffic. This leads towards a vision for global traffic control (Corbet, 1992), not just confined to port areas and canals and their approaches. The goal of this analysis is to identify the main routes in the North Atlantic and to compare them on the basis of the number of reports, which is related to the intensity of the traffic.

The North Atlantic gives the reference sea state conditions for ship design and the scatter diagrams for use in design must reflect the wave conditions expected during the voyages. Design parameters, such as the significant wave height, are commonly derived from climate databases, which combine local and remote measurements and results from numerical models. However route selection is highly influenced by heavy weather (Martínez and Castells, 2008) and ships attempt to avoid dangerous 
conditions, especially in the heaviest storms. This task was traditionally dependent on the experience of the captain and alerts from meteorological institutions (Hilder, 1958; Cotter et al., 1966; Del Prete et al., 1999), but sophisticated weather routing systems integrated in on board equipment (Szłapczyńska, 2013) are increasingly being adopted. These tools might be of remarkable help in the route selection process. North Atlantic passages last several days and are thus compatible with relatively accurate forecasts.

It has become clear that the weather that a ship experiences during its lifetime can be significantly different when estimated from the available databases. This aspect changes according to the type of ships providing the voluntary observations, as different ships and their cargo are sensitive to weather in different ways and thus have different levels of motivation to avoid storms.

The wave information that has been used for establishing the reference conditions for the design of ships has been the data set from Global Wave Statistics (GWS) visual observations (Hogben et al., 1986) collected from ships in normal service all over the world since 1949. Visual observations carry significant uncertainty and several studies have been made to quantify and correct them for the bias as discussed, for example, in Guedes Soares (1986a,b). Other databases of this type of information also exist and it has been shown that they can lead to substantially different predictions of the most likely maximum loads in ships to be used for their structural design (Guedes Soares, 1996). The GWS data consist of scatter diagrams of significant wave height and zero-crossing wave period, which are given for different seasons and directions. The data do not include information about the wave spectrum, which is important and can be obtained from the modern databases of hindcast data (Lucas et al., 2011). However it includes information as a function of wave direction and this has been shown to be relevant in long term predictions (Guedes Soares, 1995).

Nowadays other types of data have become available from numerical wave models and remote sensing, which have produced large datasets of consistent wave data that can be used to establish wave climatologies over ocean areas (Barstow et al., 1995; Uppala et al., 2005; Pilar et al., 2008). These data sets although of good quality are appropriate to provide information of average and moderately high wave conditions, (Campos and Guedes Soares, 2012) but still suffer from inaccuracies for predictions of extreme values (Bitner-Gregersen and Guedes Soares, 2007), which will be reflected in the predicted maximum wave loads in various types of marine structures (Guedes Soares and Viana, 1988; Guedes Soares and Trovão, 1991).

The climate data sets are a good basis to describe the wave conditions for offshore structures that are in fixed positions. However ships tend to avoid heavy storms and in rough weather conditions may change course and speed to alleviate the motions and loads imposed on them by the waves (e.g Guedes Soares, 1990). Therefore, to be able to use these data sets in an appropriate way, it is necessary to understand the effect of storm avoidance, which is one of the objectives of this paper. The comparison of boreal winter and summer tracks will give some qualitative indications on the effect of heavy winter storms in the preferred ship tracks.

The study of the maritime trade system is usually focused on economical and logistical considerations (Fremont, 2007; Hu and Zhu, 2009; Kaluza et al., 2010). Port operations are analysed in order to retrieve information about the network system, rather than actually map the trajectories at sea. When the ships' paths have to 
be detected there are not many sources to study. If a specific area is considered, radar observations can be used (Yao et al., 2010), but on ocean-crossing routes a semi-empirical approach is required.

The Voluntary Observing Ship (VOS) program (Fletcher, 2008) provides a unique source of geo-referenced reports, which, besides giving a huge dataset of meteorological parameters, specify the exact position of each observing ship during its operations. Since there is no reason to suppose that the percentage of ships participating in the VOS program is changing from one route to the other (the analysis is only limited to the North Atlantic sub-basin), it can be assumed that the density of observations is a good approximation of the density of ships on the routes. Using the Automatic Identification System (AIS) to determine the ship positions could be an alternative way of identifying the ship routes. This has been done already but only on routes close to coastal areas where AIS data is easier to collect systematically (Silveira et al., 2013).

Another factor that can be helpful in this attempt is a brief consideration of the geomaritime-economy. On the east side of the North Atlantic, most of the trans-oceanic routes originate either in the Channel or in the Strait of Gibraltar for obvious reasons. Contrarily, on the west side, the amount of cargo volume of the ports relative to the foreign trade can give the idea of the major shipping regions on the North American Atlantic coast.

Finally, the present work may be interesting for a comparison with considerations on past ocean routing charts (Dickson, 1962), which indicates the historical evolution of the ocean passages.

2. VOLUNTARY OBSERVING SHIPS PROGRAM. The international scheme by which ships plying the various oceans and seas of the world are recruited by National Meteorological Services (NMSs) for taking and transmitting meteorological observations is called the World Meteorological Organization (WMO) Voluntary Observing Ships' scheme. The forerunner of the scheme dates back as far as 1853 (Kent et al., 1993).

At the present time, the contribution that VOS meteorological reports make to operational meteorology, to marine meteorological services and to global climate studies is unique and irreplaceable. During the past few decades, the increasing recognition of the role of the oceans in the global climate system has placed even greater emphasis on the importance of marine meteorological and oceanographic observing systems.

These ship observations provide ground truth for the satellite observations, important information which the satellites cannot observe, essential contributions to the data input for the Numerical Weather Prediction (NWP) models, and real-time reports which can be used immediately in services for the mariner.

A peak in total VOS was reached in 1984/85 when about 7700 ships worldwide were on the WMO VOS Fleet List. Since then there has been an irregular but marked decline and in June 1994, the Fleet strength dropped to about 7200 ships. These numbers have continued to decline and are currently estimated at only about 4000 ships worldwide. Besides commercial ships (tankers, bulk carriers, container-ships, etc.), also fixed platforms are involved in the program, but their reports have been removed in the pre-processing phase due to the nature of this analysis. 
The global number of available observations in the period 1950-2001 is around 100 billion, of which approximately a third are in the North Atlantic area. However, only $40-60 \%$ of the total number of reports includes wave information (Gulev and Hasse, 1998).

As might be expected, real-time reports from the VOS are heavily concentrated along the major shipping routes, primarily in the North Atlantic and North Pacific. While there are wide areas where the number of reports is really poor, especially in the southern oceans, it can be considered representative of the maritime traffic in the North Atlantic and North Pacific sub-basins. The large number of merchant ships involved in the program operating on those tracks ensures a statistically consistent sample of maritime trade.

3. ROUTE DETECTION. The first and essential step is the identification of the most common trajectories in the ocean passages. Since oceans represent a continuous domain, a ship can theoretically choose infinite routes between one port and the other. It is then necessary to choose a discretization scheme and look for the most common paths, which depend on both physical and economic factors.

While close to the coast the tracks can be detected by radar observations (Yao, 2010), offshore the only available sources that include a considerable number of ships are the VOS reports. Among many other parameters mainly of meteorological nature, ships involved in this program provide, of course, their own geographical position and they are asked to ensure four reports per day. The VOS dataset thus becomes an irreplaceable source for route tracking in long oceanic passages.

In Figure 1 the density of VOS reports near the east coast of the US is depicted using a grid of $2^{\circ}$ by $2^{\circ}$. Although all along the coast ship concentration is obviously much higher than in the open ocean, it is possible to distinguish three principal junction points through which the ocean tracks seem to direct: one north east corresponding to the area of New York and Virginia, the southern part of Florida as a gate for the Gulf of Mexico and Puerto Rico for the Caribbean Sea.

In spite of the well known economical relevance of the Gulf of Mexico in the global and American trades (that will be confirmed later on), Atlantic passages towards this area do not appear to be predominant. In fact, the US foreign trades that concern the Gulf are mainly with Central and South America and the Pacific Ocean.

The American Association of Port Authorities provides the ranking of U.S. Customs Districts for waterborne foreign trade (U.S. Waterborne Foreign Trade, 2010). In Table 1 these districts are divided by region considering the fact that the ships transiting from one point in Europe towards different ports of the same region follow similar tracks.

As expected, the Gulf of Mexico is inarguably the most important area for US maritime shipping. This is mainly due to the relevant impact of the blooming oil and gas industry and the proximity to the Panama Canal. Currently about $15 \%$ of the containers from Asia that transit the Canal are directed to Houston.

The dynamic industry trends of the north east of the US and the increasing tendency towards containerisation, which is aimed at making overseas shipping more cost effective, stimulated a dramatic growth in these waterborne trade districts. The northernmost stream of the Atlantic Ocean is directed towards this area. 


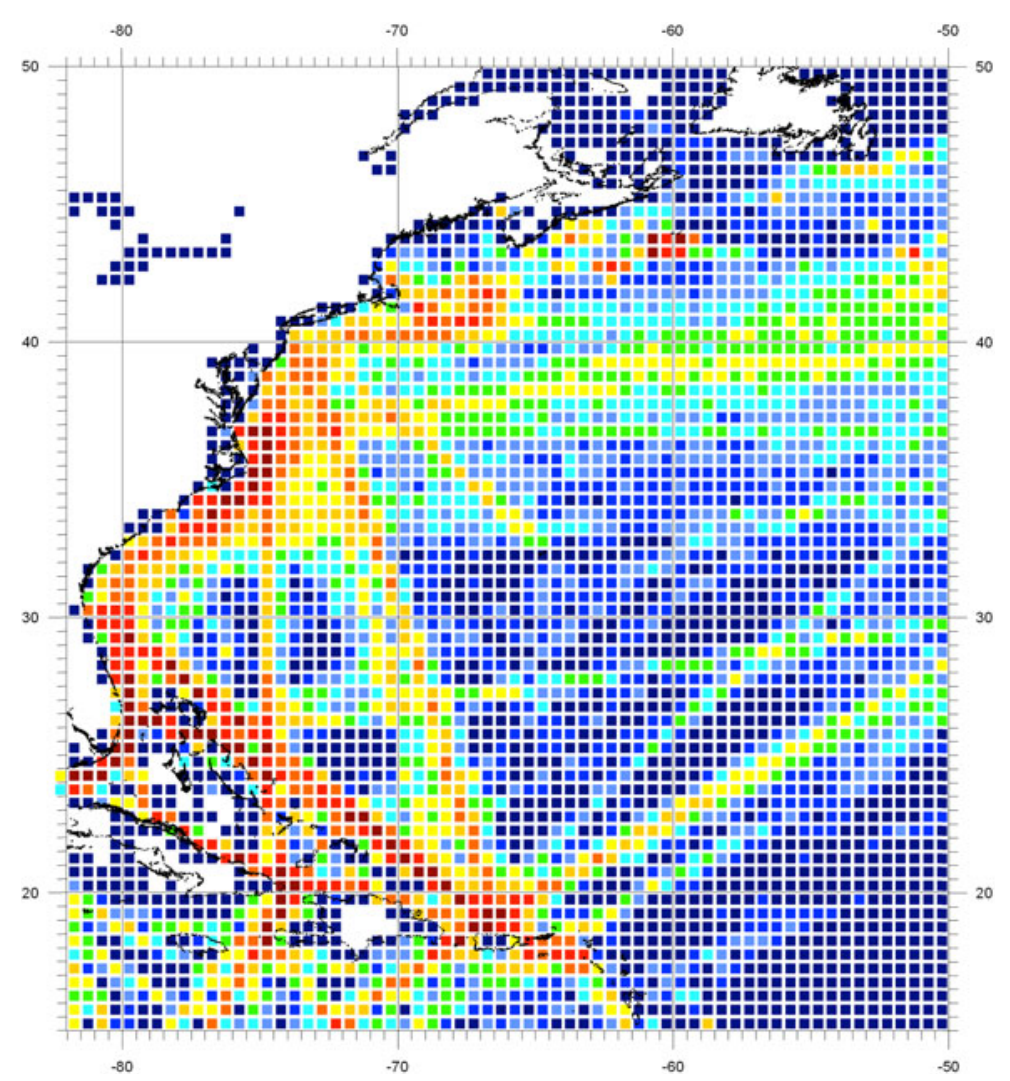

Figure 1. Density (number of reports per panel) of VOS observations approaching the US coast, increasing from blue to red.

Although the relative importance of San Juan (Puerto Rico) and Virgin Islands harbours in the US maritime economy is much smaller than the other regions, Figure 1 clearly highlights a crucial crossroad in that area, because of the importance of the Panama Canal, for shipping between Europe and the Pacific, and also of the trades between Europe and northern South America.

Considering both the distribution of the foreign market in these regions and the density of VOS reports (Rossby et al., 1995) approaching the US coast, it is then easy to identify the three main junctions approximately corresponding to the area of Puerto Rico for the Caribbean Sea, Miami for the southeast coast of US and the Virginia area for the northeast coast.

At this stage, all VOS reports from January 1990 to January 2009 are considered, that is to say more than 2.5 million reports. Even though the global economy continuously changes, it is assumed that this time period reflects better the recent condition and trend.

In order to discard the effect of the cabotage trade and the routes towards the southern Atlantic sub-basin, the data closer to the coast is removed. So the number of the remaining reports is reduced, maintaining more than 1.5 million. The resulting density is shown in Figure 2. 
Table 1. U.S. East Coast waterborne foreign trade regions.

\begin{tabular}{lllr}
\hline Region: Gulf of Mexico & CUSTOMS & DISTRICT & 1000 TONS \\
RANK & Houston-Galveston & TX & 262163 \\
1 & New Orleans & LA & 257440 \\
2 & Port Arthur & TX & 64650 \\
5 & Mobile & AL & 54260 \\
8 & & & TOT $=638513$ \\
& & & \\
Region: North East Coast & CUSTOMS & DISTRICT & 1000 TONS \\
RANK & New York City & NY & 86060 \\
4 & Norfolk & VA & 56845 \\
6 & Philadelphia & PA & 55936 \\
7 & Baltimore & MD & 34332 \\
12 & Boston & MA & 15289 \\
18 & & & TOT $=248462$ \\
& & & \\
Region: South East coast & CUSTOMS & DISTRICT & 1000 TONS \\
RANK & Savannah & GA & 33981 \\
13 & Tampa & FL & 25625 \\
14 & Miami & FL & 15897 \\
16 & Charleston & SC & 15707 \\
17 & & & TOT $=91210$ \\
& & & \\
Region: Caribbean & CUSTOMS & DISTRICT & 1000 TONS \\
RANK & U.S. & PR & 19319 \\
15 & San Juan & & 10813 \\
20 & & & TOT $=30132$ \\
& & & \\
\hline
\end{tabular}

The identification of the paths of the main routes is simply done by following the areas where the reports are denser between the previously defined junction points. The method is thus empirical. However the routes are quite easy to distinguish and it can be stated that the most used tracks are taken into account.

Each path is described as a number of waypoints, and then the spread of ships' positions with respect to the main route is taken into account thanks to the assignment of the reports to each route in the analysis phase.

Eight principal routes are then detected as following and depicted in Figure 3:

- Route 1: Channel-Puerto Rico (South)

- Route 2: Channel-Puerto Rico (North)

- Route 3: Channel - Virginia

- Route 4: Strait - Virginia (North)

- Route 5: Strait - Virginia (South)

- Route 6: Strait-Miami

- Route 7: East Coast-Puerto Rico

- Route 8: New York - Bermuda

In order to ensure a better description of the trades between Europe and the NorthEastern coast of the USA, route number 3 from the Channel and 4 from the Strait of Gibraltar are divided after the longitude $55^{\circ} \mathrm{W}$ and two more branches are introduced 


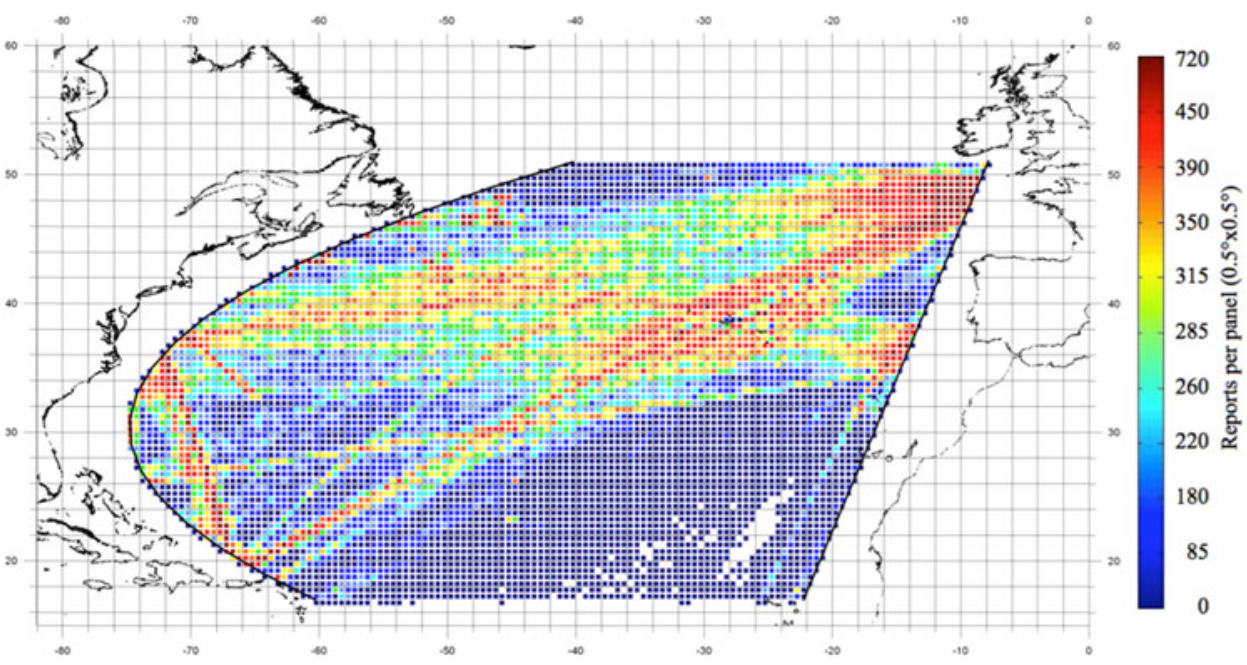

Figure 2. Density of VOS reports on the considered area increasing from blue to red.

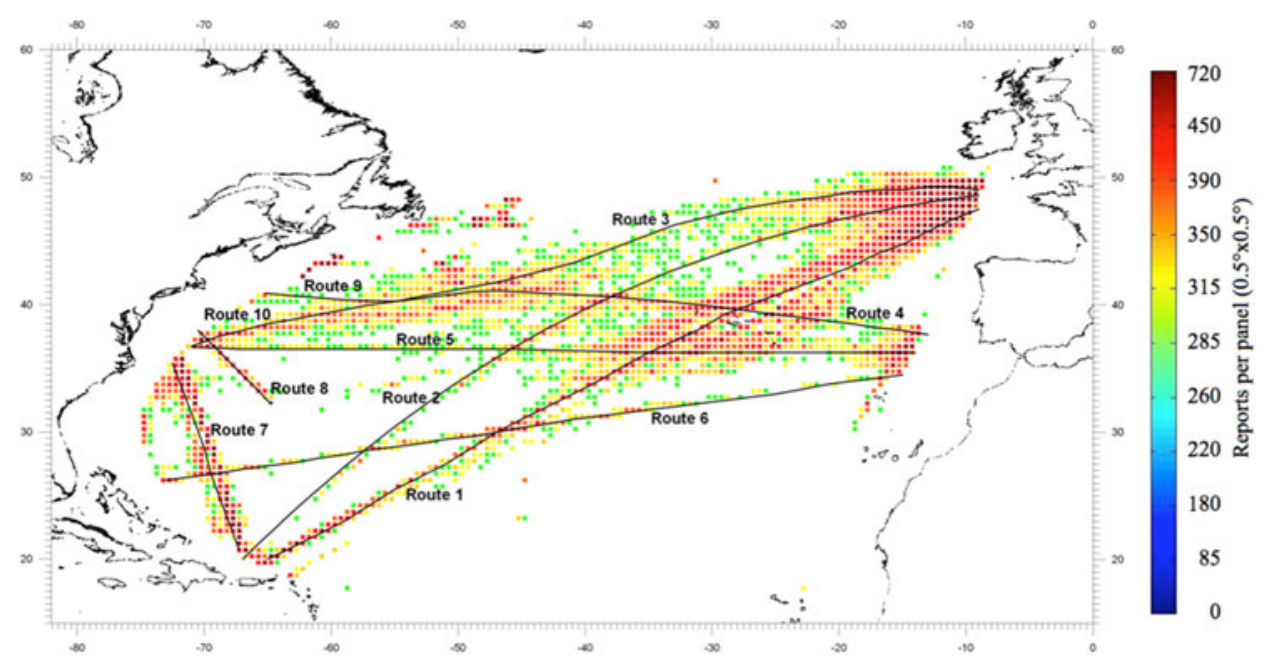

Figure 3. Main routes in the North Atlantic sub-basin.

to separately take into account the ships directed toward New York/Boston and those which will follow the main stream to the area of Virginia.

- Route 9: New York branch

- Route 10: Virginia Branch

\section{ANALYSIS OF THE MAIN ROUTES}

4.1. Ranking. To establish an unequivocal ranking between the routes, a function assigning the value for the required target, in this case the intensity of 


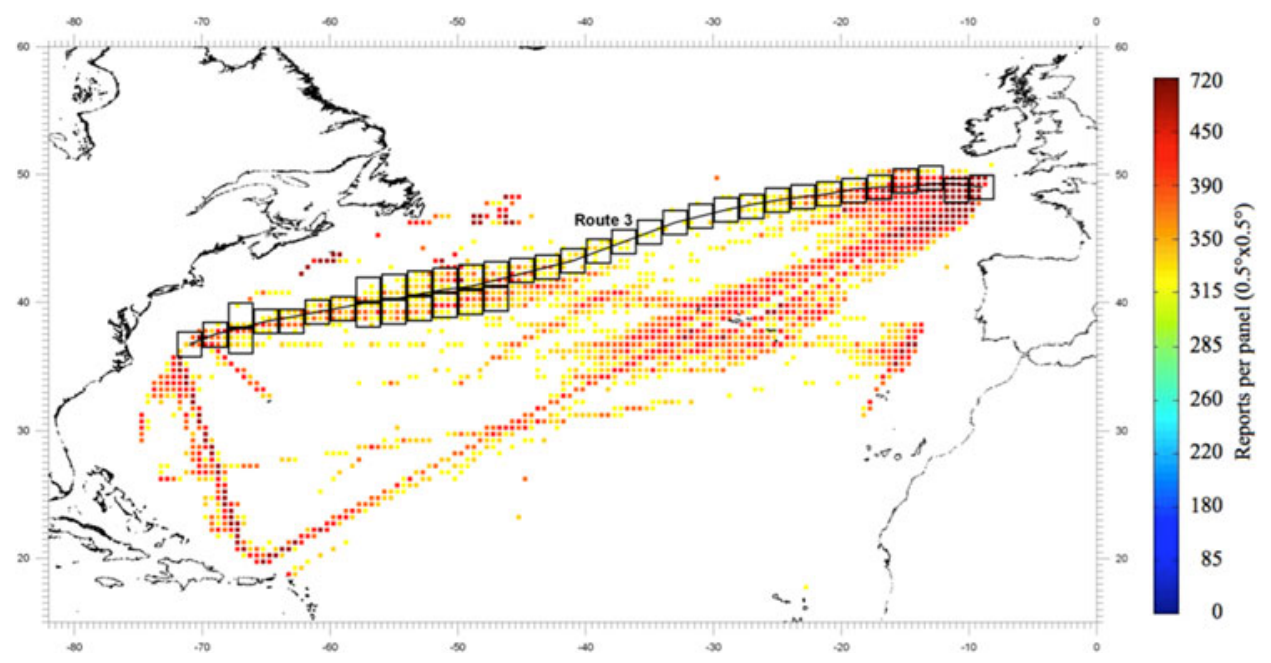

Figure 4. Example of the panel system.

traffic has to be defined. To decide which reports to assign to a specific route, a system of $2^{\circ} \times 2^{\circ}$ square areas is built along each route. In some cases the spread of the observations requires more than one area corresponding to the same location on the way. In Figure 4 an example of a grid system for route number 3 plus the "Virginia branch" (route 10) from the Channel to Virginia is shown.

Since the number of reports along routes with different lengths and eventually for different periods of time are supposed to be compared, it must therefore be normalized. The chosen parameter is the number of observations per month in $100 \mathrm{~km}$ of track:

$$
P=\frac{\text { TOT } n^{\circ} \text { reports }}{\left(n^{\circ} \text { months }\right) \cdot\left(\frac{\text { route length }}{100}\right)}
$$

A report is assigned to a route if it belongs to one of the square areas of that route. Many of the routes present a crossing point; in such a case two or more routes can share the same square. In these cases an iterative scheme is followed to assign a reliable number of reports to each involved route: initially the number of observations of the shared panels is equally split and the parameter $\mathrm{P}$ is calculated. Then a coefficient equal to the ratio between the parameters of the involved routes is computed and applied to the total number of reports of the shared panel, resulting in the updated number of reports to be assigned to the routes. The loop is repeated until convergence is reached.

The parameter $\mathrm{P}$ does not have references in literature to be compared with, thus one cannot have an immediate impression of the relevance of the traffic just knowing that parameter. Another value that can provide useful information is the percentage of reports per unit length. This percentage gives a picture of the relevance of one path with respect to the other ones analysed. The limit of the percentage is that it estimates the relationship only among the considered routes. 
Table 2. Analysis of the selected routes from 1990 to 2012.

\begin{tabular}{lcccrc}
\hline & $\begin{array}{c}\text { Length } \\
{[\mathrm{nm}]}\end{array}$ & $\begin{array}{c}\text { TOT n } \\
\text { reports }\end{array}$ & $\begin{array}{c}\% \text { of } \\
\text { reports }\end{array}$ & \multicolumn{1}{c}{ P } & $\begin{array}{c}\text { \% of reports } \\
\text { per unit } \\
\text { length }\end{array}$ \\
\hline Route & 3210 & 195731 & $22 \cdot 6$ & $13 \cdot 7$ & $12 \cdot 7$ \\
Route 1: Channel - Puarto Rico (South) & 3253 & 120345 & $13 \cdot 9$ & $8 \cdot 3$ & $7 \cdot 7$ \\
Route 3: Channel - Puerto Rico (North) & 2029 & 118519 & $13 \cdot 7$ & $13 \cdot 1$ & $12 \cdot 2$ \\
Route 4: Strait - Virginia (North) & 1958 & 98402 & $11 \cdot 3$ & $11 \cdot 3$ & $10 \cdot 5$ \\
Route 5: Strait - Virginia (South) & 2762 & 105343 & $12 \cdot 1$ & $8 \cdot 6$ & $8 \cdot 0$ \\
Route 6: Strait - Miami & 3048 & 85401 & $9 \cdot 8$ & $6 \cdot 3$ & $5 \cdot 8$ \\
Route 7: East Coast - Puerto Rico & 920 & 59106 & $6 \cdot 8$ & $14 \cdot 5$ & $13 \cdot 4$ \\
Route 8: New York - Bermuda & 448 & 18475 & $2 \cdot 1$ & $9 \cdot 3$ & $8 \cdot 6$ \\
Route 9: New York branch & 471 & 19497 & $2 \cdot 2$ & $9 \cdot 3$ & $8 \cdot 6$ \\
Route 10: Virginia branch & 782 & 46660 & $5 \cdot 4$ & $13 \cdot 4$ & $12 \cdot 5$ \\
\hline
\end{tabular}

For these reasons, within the limit of one analysis the percentage allows an easier comparison, while if the study has to be repeated in a different region, the parameter $\mathrm{P}$ will represent a more useful standardization. Hence, both the values are reported.

Considering a period of 20 years from January 1990 to December 2009, the result is summarised in Table 2.

It must be noted that the length of the routes is only relative to the considered part, not to the actual distance between the geographical points. The portion that is closer to the coast has been excluded (see Figure 4). Therefore, it appears that the shortest route from the Channel to Puerto Rico is the southern one, even though the northern route is the great circle and thus it is shorter (but the considered extreme points are not the same). Furthermore some routes are split into two, so for a correct comparison of routes 4 and 5 , the length of the former has to be added to the length of the "Virginia branch", resulting in $2740 \mathrm{~nm}$.

These considerations do not compromise the present analysis, but they should be taken into account for future comparisons.

4.2. Seasonal cycles. Although the parameter $\mathbf{P}$ has no absolute references in literature to be compared to, it allows the understanding of how much a route is used in different periods. When two routes have to be compared, it is better to use the percentage per unit length, taking into account only the relationship between the trajectories that are being considered, discarding the global variability of trades and therefore the total number of reports.

The seasonal cycles of the considered routes are reported in Figure 5. The southern routes, such as numbers 5 and 6 , generally present a more consistent behaviour.

On the other hand, when the northern latitudes are involved, the effect of weather is much more visible and it is reflected by an increase in traffic in the months between spring and summer when the mean Significant Wave Height (SWH) is lower than $2 \mathrm{~m}$ in the whole of the North Atlantic (Figure 6(a)).

In winter, with the presence of the heavier extra-tropical storms and mean SWH even more than $4 \mathrm{~m}$ height north of the $40^{\text {th }}$ parallel (see Figure 6(b) and Semedo et al., 2011), the ships tend to prefer a southern course between the two ports (see Section 3.3) or even plan the yearly schedule, aiming to avoid those areas in winter. 

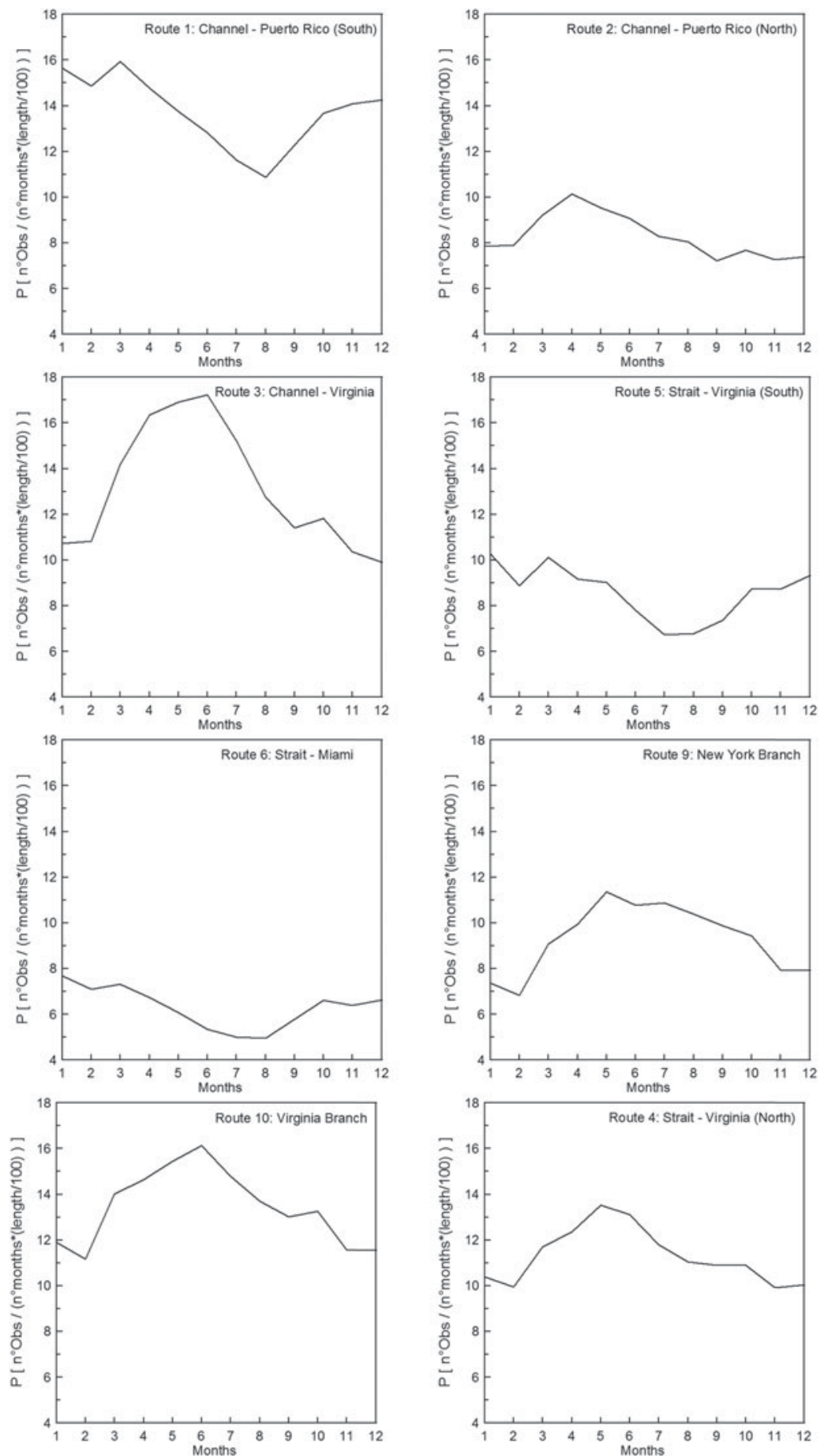

Figure 5. Seasonal cycles for the considered route. 
a)

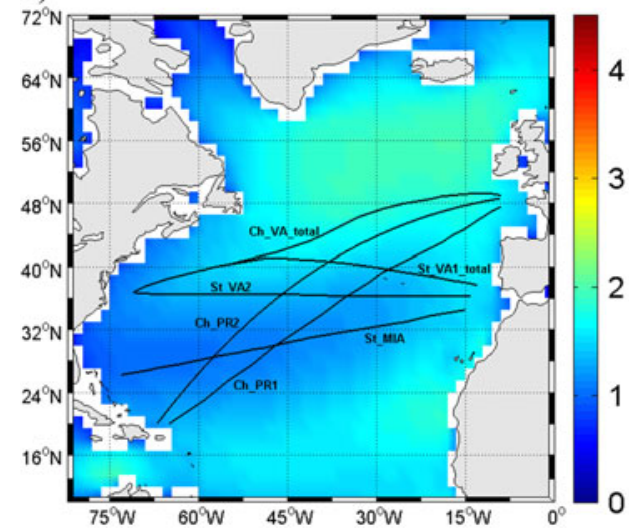

b)

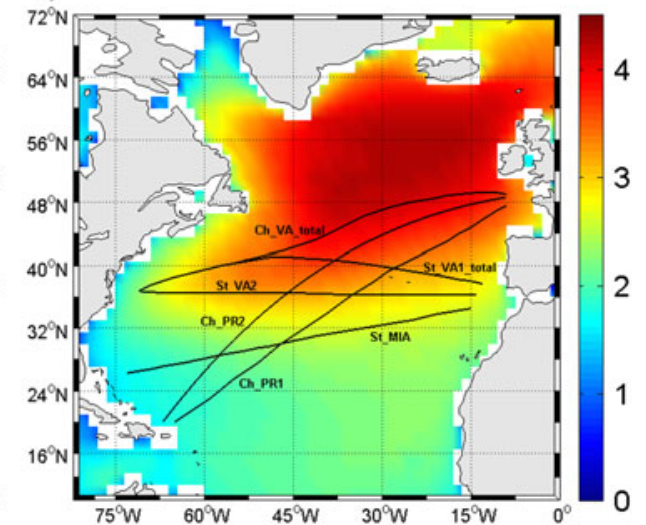

Figure 6. Maps of summer (a) and winter (b) mean significant wave height in the North Atlantic.
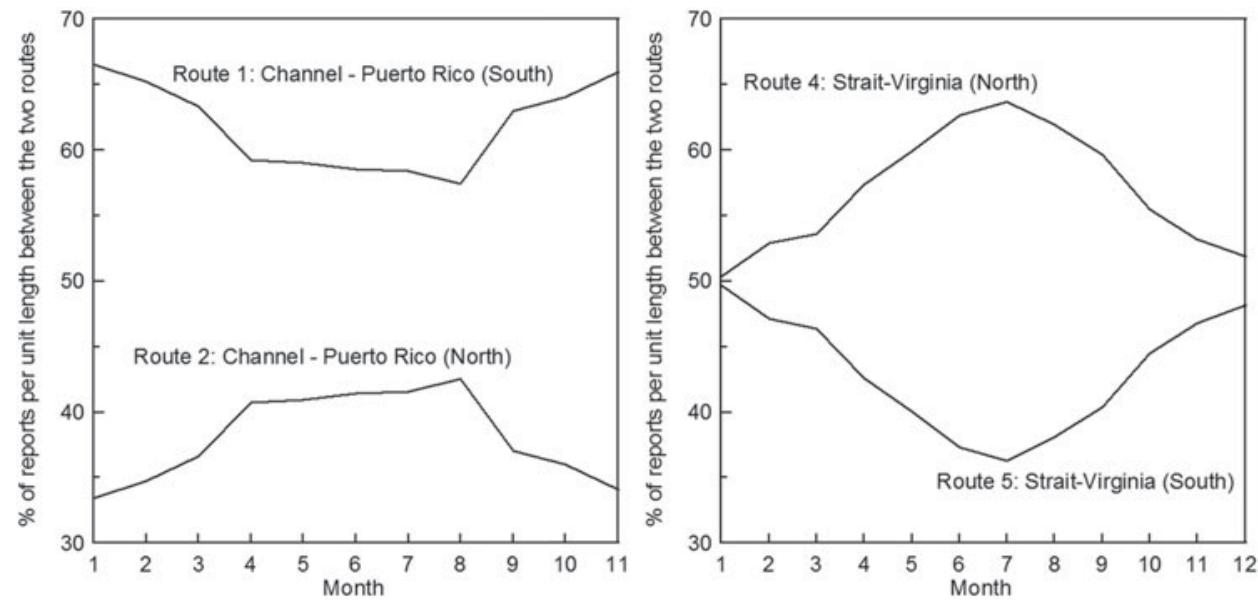

Figure 7. Comparison between Channel-Puerto Rico (a) and Strait-Virginia (b) southern and northern routes.

4.3. Comparison between northern and southern routes. A direct comparison between two routes is only really useful if the departure and arrival points are the same. For this reason, in the following analysis, routes 1 and 2 from the Channel to Puerto Rico and routes 4 and 5 from the Strait of Gibraltar to the Virginia area will be presented. In Figure 7 it is clearly shown that there is a tendency to favour the southern routes during winter months, even though they are longer.

In both cases the southern route is less used in the summer when the North Atlantic storms are less severe (Semedo et al., 2011). The trades between the Strait of Gibraltar and the Virginia area prefer the great circle (northern) route when allowed by the weather conditions, whereas for the trades between the Channel and Puerto Rico, the southern and slightly longer route is always favoured. To explain this preference, first of all it must be considered that the advantage of the great circle in terms of length is smaller in the latter case because of the northeast-southwest direction instead of 
Table 3. Trend of route usage in the decades from 1970 to 2000 (the numbers indicate the percentage per unit length).

\begin{tabular}{lccccccrc}
\hline Routes & 1 & 2 & 3 & 4 & 5 & 6 & 9 & 10 \\
\hline 1970 & $13 \cdot 6$ & $9 \cdot 5$ & $11 \cdot 9$ & $7 \cdot 6$ & $6 \cdot 9$ & $5 \cdot 5$ & $9 \cdot 4$ & $10 \cdot 0$ \\
1980 & $11 \cdot 0$ & $8 \cdot 6$ & $13 \cdot 1$ & $9 \cdot 3$ & $7 \cdot 4$ & $5 \cdot 7$ & $10 \cdot 2$ & $11 \cdot 3$ \\
1990 & $12 \cdot 4$ & $7 \cdot 6$ & $12 \cdot 2$ & $9 \cdot 9$ & $7 \cdot 8$ & $5 \cdot 8$ & $7 \cdot 8$ & $12 \cdot 3$ \\
2000 & $13 \cdot 3$ & $7 \cdot 9$ & $12 \cdot 2$ & $11 \cdot 5$ & $8 \cdot 2$ & $5 \cdot 9$ & $10 \cdot 2$ & $12 \cdot 7$ \\
\hline
\end{tabular}

west-east. Secondly, the attempt to avoid the tail of the most critical storm area on the west side of Ireland (Semedo et al., 2011) as well as the risk of encountering icebergs may play a leading role in the route selection process.

4.4. Decadal variation. Unfortunately, a comparison of the parameter $\mathrm{P}$ in different decades seems to be more affected by the decrease in the number of members of the VOS program instead of the real evolution of the trades in a specific route. However, the percentage per unit length (see Table 3) can give some suggestions regarding the change in relationship among the routes through the years.

The only noticeable indications are the increasing tendency to sail the northern route between the Strait of Gibraltar and the Virginia area (route 4) and consequently in the "Virginia branch" (route 10).

5. CONCLUSIONS. The traffic crossing the North Atlantic sub-basin was analysed through VOS report data. Ships enrolled in the VOS program are just a fraction of the total number of ships carrying goods across the oceans. Nevertheless, the attention paid in order to ensure a diversified and statistically meaningful fleet allows us to consider it a good sample of the maritime traffic in the North Atlantic.

The applied procedure has a considerable empirical component, thus the results may slightly differ if the selected coordinates for the routes and the panels are changed. Although some simplifications were adopted, useful considerations can be made. Storm avoidance influences the choice of the course and it is mainly highlighted on the northern routes, which are always less frequented in winter. Routes involving the Virginia area, especially from northern Europe, are the ones with the higher seasonal variability and minor traffic in winter. Overall, May is the month with the highest presence of ships, whereas in December it reduces by almost $20 \%$.

Considering just the trans-oceanic passages (routes 1 to 6 ), the results show that the most travelled route is the one from Northern Europe (the Channel) to the Caribbean Sea (routes 1 and 2) with $36 \%$ of the traffic in the considered areas (higher percentages in winter). More than one-third of these ships prefer the northern and shorter orthodrome; in August this percentage rises to 43\%.

The stream between the Strait of Gibraltar and the North-East Coast of the USA (routes 4 and 5) denote a similar concentration with about $32 \%$ of the trades, while the routes from the Channel to the Virginia area (route 3) and from Gibraltar to Miami (route 6) contribute to $21 \%$ and $10 \%$ respectively.

This distribution can be attributed to the presence of the Panama Canal that is the only practical way to reach the Pacific side from Northern Europe. On the other hand, many of the ships passing through the Strait of Gibraltar are directed 
(or come from) the Suez Canal, while only a small number of them operate in the Mediterranean Sea. Finally, due to the crossing of the two main trans-oceanic streams, the offshore area with the most intense transit is in correspondence to the Archipelago of the Azores.

\section{ACKNOWLEDGEMENTS}

This work was performed within the project SHOPERA-Energy Efficient Safe SHip OPERAtion, which was partially funded by the EU under contract 605221 . The first author was supported by the Portuguese Foundation for Science and Technology (FCT - Fundação Para a Ciência e Tecnologia, Portugal) under Contract no. SFRH/BD/89476/2012.

\section{REFERENCES}

Bitner-Gregersen, E. and Guedes Soares, C. (2007). Uncertainty of Average Wave Steepness Prediction from Global Wave Databases. Advancements in Marine Structures, Guedes Soares, C. and Das, P. K. (Eds.), London, UK, Taylor \& Francis Group. 3-10.

Barstow, S.F., Haug, O. and Krogstad, H.E. (1995). World Wave Atlas: A PC MS-WINDOWS Product for Wave Climate Assessment Globally. Proceedings of the 3rd Thematic Conference on Remote Sensing for Marine and Coastal Environments, Seattle, USA, Vol. 1, 95-103.

Campos, R. and Guedes Soares, C. (2012). Comparisons of two wind and wave data sets from the North Atlantic. C. Guedes Soares, Y. Garbatov S. Sutulo T. A. Santos (Eds.). Maritime Engineering and Technology. London, UK, Taylor \& Francis Group. 473-479.

Corbet, A.G. (1992). Towards Global Marine Traffic Control - the Need, the Technical Feasibility and the Social and Political Impediments. Journal of Navigation, 45(3), 425-439.

Cotter, C.H., Wepster, A., de M. Leathes, R.E., Rayson, J. and Page, D.M. (1966). The Training of Navigators. Journal of Navigation, Discussion, 19(3), 371-391.

Del Prete, R., Pezzoli, A. and Pezzoli, G. (1999). Current Methods for Meteorological and Marine Forecasting for the Assistance of Navigation and Shipping Operations. Journal of Navigation, 52(1), 104-118.

Dickson, A.F. (1962). Ocean Routing Charts. Journal of Navigation, 15(3), 339-341.

Fletcher, J. (2008). Meteorological observations from ships. Marine Observations Meteorological Service of New Zealand, JCOMM VOS Panel. Seaways.

Fremont, A. (2007). Global maritime networks. The case of Maersk. Journal of Transport Geography, $15,431-442$.

Guedes Soares, C. (1986a). Assessment of the Uncertainty in Visual Observations of Wave Height. Ocean Engineering, 13(1), 37-56.

Guedes Soares, C. (1986b). Calibration of Visual Observations of Wave Period. Ocean Engineering, 13(6), 539-547.

Guedes Soares, C. (1990). Effect of Heavy Weather Maneuvering on the Wave Induced Vertical Bending Moments in Ship Structures. Journal of Ship Research, 34(1), 60-68.

Guedes Soares, C. (1995). Effect of Wave Directionality on Long-Term Wave Induced Load Effects in Ship. Journal of Ship Research, 39(2), 150-159.

Guedes Soares, C. (1996). On the Definition of Rule Requirements for Wave Induced Vertical Bending Moments. Marine Structures, 9(3-4), 409-426.

Guedes Soares, C. and Trovão, M.F.S. (1991). Influence of wave climate modelling on the long-term prediction of wave induced responses of ship structures. Dynamics of Vehicles and Structures in Waves. Ed. W.G. Price, P. Temarel \& A.J. Keane, Elsevier Science Publishers, 1-10.

Guedes Soares, C. and Viana, P.C. (1988). Sensitivity of the response of marine structure to wave climatology. Computer Modelling in Ocean Engineering, Schreffler, B. A. and Zienkiewicz, O. C. (Eds), Rotterdam: A.A. Balkema Pub, 487-492.

Gulev, S.K. and L. Hasse (1998). North Atlantic Wind Waves and Wind Stress Fields from Voluntary Observing Ship Data. Journal of Physical Oceanography, 28, 1107-1130.

Hilder, B. (1958). On the Avoidance of Hurricanes. Journal of Navigation, 11(2), 194-206. 
Hogben, N., Dacunha, N.M.C. and Olliver, G.F. (1986). Global Wave Statistics, British Maritime Technology Ltd., Feltham.

$\mathrm{Hu}, \mathrm{Y}$. and Zhu, D. (2009). Empirical analysis of the worldwide maritime transportation network. Physica A 388, 2061-2071.

Kaluza, P., Kölzsch, A., Gastner, M.T. and Blasius, B. (2010). The complex network of global cargo ship movements. Journal of the Royal Society Interface, 7, 1093-1103.

Kent, E.C., Taylor, P.K., Truscott, B.S. and Hopkins, J.S. (1993). The Accuracy of Voluntary Observing Ships' Meteorological Observations-Results of the VSOP-NA. Journal of Atmospheric and Oceanic Technology, 10, 591-608.

Lucas, C., Boukhanovsky, A. and Guedes Soares, C. (2011). Modelling the Climatic Variability of Directional Wave Spectra. Ocean Engineering, 38(11-12), 1283-1290.

Martínez, F. and Castells, M. (2008). Heavy Weather in European Short Sea Shipping: Its Influence on Selected Routes. Journal of Navigation, 61(1), 165-176.

Pilar, P., Guedes Soares, C. and Carretero, J.C. (2008). A 44-year high-resolution wave hindcast in the North Atlantic. Coastal Engineering, 55(11), 861-871.

Rodrigue, J.P., Comtois, C. and Slack, B. (2006). The geography of transport systems. Routledge, London, UK.

Rossby, T., Siedler, G. and Zenk, W. (1995). The Volunteer Observing Ship and Future Ocean Monitoring. Bulletin of the American Meteorological Society, 76, 5-11.

Semedo, A., Sušelj, K., Rutgersson, A. and Sterl, A. (2011). A global view on the wind sea and swell climate and variability from ERA-40. Journal of Climate, 24, 1461-1479.

Silveira, P.A.M., Teixeira, A.P. and Guedes Soares, C. (2013). Use of AIS Data to Characterise Marine Traffic Patterns and Ship Collision Risk off the Coast of Portugal. Journal of Navigation, 66, 879-898.

Szłapczyńska, J. (2013). Multicriteria Evolutionary Weather Routing Algorithm in Practice. TransNav 2013, $10^{\text {th }}$ International Conference on Marine Navigation and Safety of Sea Transportation. Gdynia, Poland.

UNCTAD secretariat report (2007). Review of maritime transport 2007. United Nations Conference on Trade and Development, Geneva.

Uppala, S.M., Kållberg, P.W., Simmons, A.J., Andrae, U., da Costa Bechtold, V., Fiorino, M., Gibson, J.K., Haseler, J., Hernandez, A., Kelly, G.A., Li, X., Onogi, K., Saarinen, S., Sokka, N., Allan, R.P., Andersson, E., Arpe, K., Balmaseda, M.A., Beljaars, A.C.M., van de Berg, L., Bidlot, J., Bormann, N., Caires, S., Chevallier, F., Dethof, A., Dragosavac, M., Fisher, M., Fuentes, M., Hagemann, S., Hólm, E., Hoskins, B.J., Isaksen, L., Janssen, P.A.E.M., Jenne, R., McNally, A.P., Mahfouf, J.-F., Morcrette, J.-J., Rayner, N.A. Saunders, R.W., Simon, P., Sterl, A., Trenberth, K.E., Untch, A., Vasiljevic, D., Viterbo, P. and Woollen, J. (2005). The ERA-40 re-analysis. Quarterly Journal of the Royal Meteorological Society, 131, 2961-3012.

U.S. Waterborne Foreign Trade (2010). Ranking of U.S. Customs Districts by Volume of Cargo. American Association of Port Authorities.

Yao, C., Zhengjiang, L. and Zhaolin, W. (2010). Distribution Diagram of Ship Tracks Based on Radar Observation in Marine Traffic Survey. Journal of Navigation, 63(1), 129-136. 